\title{
Finance-seeking behaviour and outcomes for small and medium-sized enterprises
}

\author{
Dong Xiang \\ International Institute for Financial Studies \\ Jiangxi University of Finance and Economics \\ China
}

Andrew C. Worthington

Accounting, Finance, and Economics

Griffith University

Australia

\begin{abstract}
Purpose - Model finance-seeking behaviour and outcomes by Australian small and medium-sized enterprises (SMEs) using firm-level panel data.

Design/methodologylapproach - Use firm-level three-year panel data for more than two thousand SMEs from the Business Longitudinal Database compiled by the Australian Bureau of Statistics, we estimate separate models for the seeking of finance (debt and/or equity) and the outcomes of financeseeking (successful or unsuccessful). Key explanatory variables include declared business focus (on financial, cost, operational, quality, innovation, and human resource measures), presence of business plans and other documentation related to successful finance seeking, innovation, indicators for family and foreign-owned businesses, and profitability. Control variables include sales, the number of employees, length of operations, export and import activity, government financial assistance, and industry classification.
\end{abstract}

Findings - Business objectives together with a large number of firm-level characteristics, including firm age, size, industry and sales, profits, growth and exports, significantly affect both finance-seeking behaviour and outcomes. We find evidence that the pecking order and agency cost theories of capital structure at least partly explain the financial behaviour of Australian SMEs.

Research limitations/implications - Several of the responses in the underlying survey data are qualitative so we are unable to assess how the strength of these relationships varies by the levels of sales and profitability.

Practical implications - Our findings show that business objectives significantly affect SME financeseeking decisions and outcomes. SMEs that focus on profitability or growth have a strong willingness to seek additional finance; in comparison, SMEs that focus on the quality of their products or services are less likely to apply for additional finance. As only half of the SMEs in the sample considered profitability or growth to be a major business focus, core business objectives greatly affect SME financing decisions. Further, pecking order theory not trade-off theory better explains the financial behaviour of SMEs, yielding evidence that SMEs continue to face financial constraints when pursuing growth. Some evidence also of agency cost theory in the positive effects of family ownership on debt seeking.

Originality/value - One of very few studies to examine finance seeking by SMEs, especially in Australia. Further, only study known to include declared business strategy, presence of business plans and other finance-related documentation and innovation in addition to the usual focus on growth and profitability to explain financing behaviour. Very large panel of longitudinal data used to explain financial decision-making over time.

Keywords: Small and medium-sized enterprises, financing decisions, capital structure, debt and equity

Article Classification: Research paper 


\section{Introduction}

It goes without saying that small and medium-sized enterprises (SMEs) are economically important, not least in Australia. In evidence, small (0-19 employees) and medium (20-199 employees) businesses (the standard definition of SMEs used in Australia) respectively represent $96 \%$ and some $4 \%$ of Australia's nearly 2.1 million trading enterprises, accounting for $35 \%$ and $22 \%$ of value-added, and $47.2 \%$ and $23.3 \%$ of employment (Department of Innovation, Industry, Science, and Research, 2011). It is equally manifest that SMEs generally lack appropriate finance and therefore require special attention because of their inherent informational opaqueness and the limited finance sources commensurately available (Beck et al., 2005, 2008). A better understanding of the how, when and why of SMEs seek finance and any outcomes then allows to us to improve industry practice and inform government policy so that this sector is not habitually starved of the funds necessary for sustainable growth and development.

The purpose of this paper is to model the firm-level determinants of financeseeking behaviour and outcomes for SMEs in Australia. In doing so, our study contributes in the following ways. First, we control for business strategies or objectives in our analysis. Given SMEs can be very different from large firms in terms of their operations, business objectives may closely relate to the need for external finance by SMEs. For example, a more aggressive strategy of business expansion will typically require more external finance than a more passive strategy. SMEs also tend to promote profit stability rather than profit maximization (Hamelin, 2011). However, there is little existing work on the impact of stated business objectives on finance seeking by SMEs. Using a comprehensive dataset, we find that a focus on profitability or growth is associated with a strong willingness to seek additional finance, whereas SMEs that focus on the quality of their products or services are less likely to apply for additional finance.

Second, using firm characteristics across three categories of potentially influential factors, namely, organizational, operational and market factors, we are better able to evaluate the prevailing capital structure theories. We find that pecking order theory, as compared to trade-off theory, better explains the financial behaviour found among Australian SMEs. This is especially important when we recall that apart from Romano et al. (2001), no existing study has rigorously tested the application of capital 
structure theories to SMEs in Australia. Third, we examine both the demand-side determinants of finance seeking and the firm-level (supply-side) factors affecting the availability of finance. In doing so, we achieve a better understanding of SME financing behaviour and outcomes, in particular why SMEs seek finance, and if they do seek finance, what determines whether they are successful. Lastly, for the policy makers, our findings are useful for the design of small business policy.

We find that business objectives have a significant effect on SME financing behaviour, in that SMEs that focus on profitability or growth actively seek additional finance. However, business objectives apparently do not affect the availability of finance, with the investors and creditors seemingly paying greater attention to their creditworthiness. SMEs with good profitability and those receiving some form of government assistance are also more likely to obtain finance.

The remainder of the paper is organized as follows. Section 2 briefly discusses the relevant literature. Section 3 details the hypotheses, Section 4 presents the model specifications, and Section 5 describes the data. Section 6 discusses the results. Section 5 provides some concluding remarks.

\section{Review of the literature}

A sizeable literature focuses on the restricted capability of SMEs to obtain finance because of their inherent informational opacity (e.g. Beck et al., 2005, 2008; Berger and Udell, 2006; Dietrich, 2012). All of these studies encompass two broad dimensions; that is, the supply and demand side of SME financing. On the supply side, numerous studies have suggested that SMEs are less likely to have access to formal sources of finance, such as securitised debt and equity markets. Thus, SMEs rely relatively heavily on intermediated finance from banks and other financial institutions (Iturralde et al., 2010). However, banks may wish to have less exposure to SMEs or want to charge SMEs relatively higher fees and interest rates compared with larger firms (Beck et al., 2008). In addition to high levels of operational costs, SMEs have a severe lack of negotiation power (Dietrich, 2012) because the alternatives to bank finance are even more costly (Roberts and Sufi, 2009). Therefore, financial obstacles consistently adversely affect SMEs borrowing and thus they frequently rely on internal finance (Beck et al., 2005, 2008). 
However, that SMEs depend heavily on internal finance may also result from the unwillingness of SME owners to seek external finance. For example, some SME principals may use retained earnings to obtain a larger equity share by buying out joint-owners and insider debt. Thus, the equity share of the principal owner increases over time. We cannot neglect these factors affecting the demand for finance in SMEs. On the demand side of SME financing, a number of studies apply the conventional large-firm theories of capital structure, that is, the pecking order, trade-off, and agency costs theory, to investigate the financing decisions of SMEs. For example, Lopez-Gracia and Sogorb-Mira (2008) demonstrate that both trade-off and pecking order theory help to explain SME capital structure and that Spanish SMEs are more likely to aim to reach a target or optimal degree of leverage according to trade-off theory. As an alternative, Bartholdy and Mateus (2011) argue that for small firms, restrictions on debt in the balance sheet are less apparent than for large firms, which makes it easier for small firms to exploit the tax advantages of debt.

In a similar vein, using a Belgian dataset, Caneghem and Campenhout (2012) conclude that both the quality and quantity of information positively relate to SME leverage. In their study, the negative relationship between profitability and leverage is consistent with the pecking order theory, whereas the significant positive coefficient for median industry leverage provides support for the trade-off theory. Furthermore, they observe a positive relationship between asset tangibility and leverage, which is consistent with agency costs. However, accounting for the limited capacity to obtain access to external finance and the informational opaqueness of SMEs, tax rates may not significantly influence the level of debt in SMEs, and asymmetric information can be a key factor that affects the finance decision-making of a SME. Thus, pecking order theory may be more prevalent among SMEs (Bhaird and Lucey, 2010; Batholdy and Mateus, 2012).

In addition, the need to obtain external funds is equally likely to drive changes in the capital structure of SMEs as an attempt to achieve an optimal capital structure (Psillaki and Daskalakis, 2009). Put differently, the willingness of SMEs to seek finance may heavily influence their need for external funds. The willingness phenomenon is closely associated with SME characteristics, along the characteristics of their owner. A number of studies investigate the influences of owner characteristics, including gender, education, age, ethnicity, wealth, on SME financing decisions 
(Fraser 2009; Roper and Scott, 2009; Bellucci et al., 2010). Unfortunately, quality data about SME owners are normally difficult to acquire because of privacy concerns (Bhaird, 2010). This is a problem in that the effects of SME characteristics on financial decision-making may be relatively more important in explaining SME financing than they are for larger firms.

We can headily divide these firm characteristics into three categories of potentially influential factors as they relate to the firm's organization, operating, and marketing, respectively. Characteristics such as ownership, firm size, firm age, employment, registration, are included in the organizational category. The operational category includes business goals, financial objectives, operating assessment, planning, innovation or growth opportunities, and profitability, etc. The final category describes the state of the market, including primary markets for the firm's output, imports, exports, and the like. A few studies investigate the effects of some of the factors in the first category on financial decision making in SMEs, such as firm size, firm age, and ownership. For example, Beck et al. (2006) report the significant effect of size, age, and ownership on financial obstacles in SMEs. A further group of studies focuses on the relationship between profitability and/or size and/or debt, thus yielding deductive evidence as to whether SMEs follow capital structure theory and theories on the relationship between growth opportunities and financing (Bhaird and Lucey, 2010; Caneghem and Campenhout, 2012).

In particular, propositions related to profit maximization can limit the validity of any attempt to investigate the factors involved in SME financing decisions. For example, Hamelin (2011) concludes that SMEs tend to promote profit stability rather than profit maximization. Further, very few SMEs appear not to be managed in such a way as to minimize intrusion in their business; thus, debt is often preferred to equity because of the low risk of losing control and decision-making power (Psillaki and Daskalakis, 2009). Moreover, SMEs sometimes appear to be unaware of which particular type of financing is more appropriate and when (Berger and Schaeck, 2011). Surprisingly, there is little existing work on determinants relating to the second category of factors, such as business objectives, planning, and markets, although there are some exceptions, including Romano et al. (2001) and Vos et al. (2007). 


\section{Theory Development}

The focus of this paper is on the firm-level determinants of SME finance-seeking and outcomes as based on the prevailing capital structure theories, namely, pecking order, trade-off, and agency costs theory. For this purpose, we seek to obtain empirical verification of the following hypotheses.

\section{Business objectives}

As discussed, business objectives may closely relate to the need for external finance by SMEs. Given SMEs can be very different from large firms in terms of their operations, not all SMEs aim to seek significant growth. For example, "Mum-andDad" SMEs do not typically pursue a high-growth strategy. Instead, the owners of many SMEs may merely enjoy operating the SME itself (Vos et al., 2007). It is therefore likely that desires for independence and control are the keys reasons for differences in SME financial behaviour. We hypothesise that business strategy helps explain both the need and motivation for seeking finance and the ability to obtain finance. For example, a more aggressive strategy of business expansion will typically require more external finance than a more passive strategy. Financers (of both debt and equity) are also more likely to reward loan applications and business plans for these types of strategy when providing finance. As discussed, there is surprisingly little extant work on the determinants of SME finance seeking in relation to business objectives and strategies, even though the literature well describes the need (Romano et al., 2001).

\section{Business planning}

We distinguish between two forms of business planning, the planning process and the written business plan, both of which positively influence SME performance when measured as profitability and sales growth (Gibson and Cassar, 2005). In addition, a start-up or early-stage SME may require a formal business plan that is used as a sales document to obtain angel finance. For instance, Romano et al. (2001) suggest that planning in Australian family businesses is positively associated with debt. Formal and/or informal planning can also act as soft information for the SMEs in that it can help alleviate opaqueness in SMEs, thus granting easier access to financial resources. 


\section{Innovation and growth opportunities}

Innovation-defined as the process of the adoption of internally or externally generated devices, systems, policies, programs, processes, products or services that are new to the adopting organization-is a proxy for growth opportunities. The influence of innovation or growth opportunities on a firm's finance decision-making has been widely discussed. This reveals that by reducing debt, firms with growth opportunities may avoid shareholder-creditor conflicts. Moreover, debt can act as a mechanism to alleviate agency cost by disciplining managers. Therefore, a firm with growth opportunities may need less debt (Fama and French, 2002). However, given the assumption that SMEs face financing constraints, those with growth opportunities are more likely to exhaust internal funds and require additional funds. In combination with the traditional concern of SMEs with control and independence, SMEs with growth opportunities may seek external debt instead of external equity. As a result, the influence of growth opportunities on SMEs finance seeking can be either negative (Heyman et al., 2008; Lopez-Gracia and Sogorb-Mira, 2008), positive (Riding et al., 2012; Degryse et al., 2012), or neither (Psillaki and Daskakis, 2009).

\section{Profitability}

Pecking order theory suggests that a firm will tap into internal funding first, whereas trade-off theory supposes that a profitable firm gives more ground to the use of tax shields. Profitability is then a key benchmark for a firm's performance, thus helping in improved acceptance of finance applications. In line with previous work (Allen, 1993; Tong and Green, 2005), we construct the following hypotheses.

\section{Size}

Firm size can also influence access to finance by SMEs. First, the informational asymmetry between insiders and outsiders can be more severe in small firms because there is less information available in the market (Psillaki and Daskalakis, 2009). Therefore, smaller firms seek proportionately less debt. Second, profitability can positively relate to firm size (Serrasqueiro and Nunes 2008). Therefore, trade-off theory predicts that larger firms should seek more debt to benefit from the tax shields, although pecking order theory would predict that larger firms use more debt. Third, tax considerations could be of less concern for SMEs because they are less likely to generate large profits and therefore less likely to use debt for tax shield purposes. If 
this is the case, size can be negatively associated with debt. In addition, given there is a positive relationship between size and age, start-up or early stage SMEs are more likely to seek equity. Thus, we propose the following hypotheses.

Age

Firm age largely corresponds to the business cycle of SMEs. Start-up and early-stage SMEs may then resort to external equity, particularly private investors and business angels (Berger and Udell, 1998). One reason is the limited internal equity. In the startup stage, retained profits are scarce, and the personal resources of the owner are very limited. A second reason is associated with a combination of information asymmetries and potential agency problems related to the lack of a trading history. The lack of collateralisable assets can exacerbate the problem of restricted access to finance (Bhaird and Lucey, 2010). From this perspective, firm age positively relates to external finance seeking. However, as SMEs move from the start-up or early-stage to the middle-stage, they are better able to source finance from retained profits. SMEs can then replace external equity with internal equity. Consequently, firm age should negatively relate to external equity seeking. The following hypotheses reflect these competing effects:

\section{Ownership}

Ownership mainly relates to a SME owner's desire for control and the impact of the agency problem. For instance, owner-manager or family-controlled SMEs may have a desire for control and so exhibit greater aversion to the use of external equity. Therefore, external equity seeking is less likely to be a consideration for older family business owners and owners that have a strong preference for retaining family control (Romano et al., 2001). Furthermore, and as argued above, debt may help alleviate agency costs by disciplining managers. Owing to the agency problem, ownermanager family firms could then seek relatively more debt when compared with nonfamily firms. However, a number of studies suggest that the problem of agency costs may only be strictly appropriate for large firms (Serrasqueiro and Nunes, 2008; Hamelin, 2010; Niskanen and Niskanen, 2010), thus potentially improving the likelihood of acquiring debt finance. However, Fleming et al. (2005) report a positive relationship between equity agency costs and the separation of ownership and control in Australian SMEs. 
Industry

Several studies suggest the important influence of industry on firm financing patterns (Degryse et al., 2012; Caneghem and Campenhout, 2012). The trade-off theory also implies that there could be an optimal leverage ratio in an industry at which SMEs are targeted. Alternatively, we could consider industry as a proxy for several influential factors, including asset structure, asset risk, and operating characteristics. For example, Degryse et al. (2012) find that SMEs in the retail trade non-food and food industries display higher debt ratios. In addition, Degryse et al. (2012) suggest that the pecking order theory dominates the wholesale trade, retail trade food and non-food, and transport sectors, whereas, the trade-off theory dominates the catering and leisure sectors. In Australian work, Romano et al. (2001) find that firms in the service industry are less likely to use family loans, and family businesses in the manufacturing industry are less likely to use capital and retained profits.

Imports and exports

Exporting can be associated with growth ambitions, so we expect exporter SMEs to seek more funds compared with non-exporter SMEs. However, exporter SMEs bear more risk because of more rapid growth and market uncertainty. Therefore, they are more likely to have loan applications turned down compared with their non-exporter counterparts (Riding et al., 2012). We can use the same assumptions to apply to importer SMEs, though to our best knowledge, no previous study investigates the impact of imports in relation to finance seeking.

\section{Model specification}

In this paper, we seek insights into both the factors underlying a SME's decision to seek additional finance, including debt and equity, and the demand-side factors influencing the outcomes of finance applications. For these purposes, we employ the following empirical model to examine the factors involved in each of these decisions:

\section{$A P P L Y=f($ operational, organizational \& market factors)}

where $A P P L Y$ represents six different dependent variables in six separate models used to test the effects of firm-specific factors on the finance-seeking decision and its outcomes. These six dependent variables are whether a SME applies for additional finance (both debt and equity) (FINA), debt alone (DEBT), equity alone (EQUI), and 
whether finance is correspondingly available (AFINA, ADEBT and AEQUI, respectively).

We include ten variables of interest. Operational factor includes nine variables. The first six variables are dummy variables that proxy the stated business strategies of SME when assessing overall business performance. In the survey date we use, there are six response options available for the question "To what extent did this business focus on the following when assessing overall business performance.” The available options are financial measures (e.g. profits, sales, growth, returns on investments), cost measures (e.g. budget, cost per unit of output, inventory cost), operational measures (e.g. asset utilisation, on-time delivery), quality measures (e.g. customer satisfaction, defect rates), innovation measures (innovations, new value-added products), and human resources (e.g. job satisfaction, skills development). SMEs could identify more than one response to this question.

We use this information to create six dummy variables for financial, cost, operational, quality, innovation, and human resources focus, which take values of one for SMEs with a stated focus in that category, otherwise zero (FOCUF, FOCUC, FOCUO, FOCUQ, FOCUI, and FOCUH, respectively). In general, we hypothesise that declared business strategies such as financial, operational and innovation focus strategies will display positive coefficients given that that they are more financially needy in their implementation and more likely to clearly signal finance-worthiness to both lenders and investors. In contrast, the remaining focuses, i.e. cost, quality and human resources focus, which we consider as non-profitable or non-growth benchmarks, do not have a significant and positive effect on finance seeking.

The next variable, PLAN, equals one if the business has the following business activities: written strategic and business plans, budget forecasts, formal networking with other businesses, comparison of performance with other businesses, or export market plans, otherwise zero. GROW also takes a value of if the business has introduced any new or significantly improved operational or organizational processes, otherwise zero. As a proxy for the profitability of the SME, PROF is set at one if the firm has higher profitability compared to its major competitors and zero otherwise. In the organization factor category, ownership is a variable of interest where $O W N F$ is a dummy variable taking a value of one for a family business and zero otherwise. 
In our analysis, most variables in the organizational factor category and the two variables in the market factor category serve as controls. SIZE is the logarithm of sales. The age dummy variables are AGE01, AGE02, and AGE03, which are respectively set to equal one for firms that are aged less than 5 years, 10 years to less than 20 years, and 20 years or more, zero otherwise. We also include 11 dummy variables based on the two-digit Australian and New Zealand Standard Industry Classification (ANZSIC) subdivisions of agriculture, mining, manufacturing, construction, wholesale trade, retail trade, accommodation, transport, communication services, property and business services, cultural and recreation services, and personal services. ASSI is a proxy for whether the business has received any financial assistance from Australian government organizations, with a value of one if yes, zero otherwise. Lastly, EXP is the percentage of export sales to total sales, while IMP is a dummy variable with a value of one if the firm has imported goods/services into Australia and zero otherwise.

\section{Data}

In our analysis, we utilize the results of surveys included in the Business Longitudinal Database Expended CURF (BLD), conducted by the Australian Bureau of Statistics (ABS). The BLD comprises two independent samples (referred to as panels) drawn from the in-scope Australian SME populations, defined in the survey as all businesses employing fewer than 200 employees. Panel 1 is representative of the in-scope business population as at 30 June 2005; Panel 2 is representative of the in-scope business population as at 30 June 2006, with each panel surveyed once a year for the following three years. Once included in a panel, and irrespective of changes to business size or industry division, the selected business remains in the stratum originally selected. For reasons of confidentiality, the survey includes only a randomly generated ID, so it is unfortunately impossible to merge the two panels. In addition, the scope of the questions included in the 2005 and 2006 surveys was refined for the surveys in 2007. As a result, we selected Panel 1, and removed the 2007 survey from our sample. Panel 1 comprises 2,732 SMEs,. The BLD data is collected directly via the ABS Business Characteristics Survey (BCS), with the assistance of the Australian Taxation Office and Australian Customs.

Table I reports summary statistics of all the variables used in this analysis excepting the industry dummy variables. Because of missing data owing to 
respondent omission or errors in sequencing, the samples in 2005 and 2006 were 545 and 711 observations smaller, respectively. About 24\% of SMEs are from the industry of agriculture, forestry, and fishing. The second-largest group of SMEs in the sample is in the manufacturing industry (16\%) while the third-largest sample group are from the wholesale trade industry (10\%). About 30\% of SMEs are less than five years old, and $23 \%$ are in operation for more than 20 years.

\section{$<$ TABLE I HERE $>$}

Of the SMEs in the sample, 41\% applied for additional finance in 2005: 38\% applied for debt, 9\% for equity, and thus 6\% applied for both debt and equity (see Panel A in Table I). The applying rates dramatically fell in 2006 to 19\%. However, the availability of finance shows a relatively high level in both 2005 and 2006 at about $88 \%$ and $83 \%$, respectively. The average of the cost ratio stays steady over the twoyear period. About 16\% of the SMEs received financial assistance from Australian government organizations in 2005 and some 14\% in 2006.

Interestingly, in 2005 only 47\% of SMEs regarded financial measures, such as profits, sales growth, and returns on investments, as a major measure of business performance, which dropped further to $40 \%$ in 2006. Similarly, cost measures also dropped from $40 \%$ in 2005 to $34 \%$ in 2006 . However, the SMEs appear to pay more attention to quality measures, for example, customer satisfaction and defect rates, which increased from 34\% in 2005 to $37 \%$ in 2006. By comparison, most SMEs do not consider innovation as a major measure. However, more SMEs introduced new goods, services, or processes during the sample period, from 26\% of 2005 to $36 \%$ of 2006. Half of the SMEs were involved in planning activities in the business. About 26\% of SMEs were considered (by the respondents) to be more profitable compared with their major competitors in 2005 and 32\% observed an increase in profitability in 2006 compared with the previous year. In addition, 63\% of the sampled SMEs are family businesses and $4 \%$ have some degree of foreign ownership.

\section{Empirical results}

\section{Influential factors in seeking finance}

Table II reports the results from the models of the determinants of SMEs seeking finance. Both the likelihood ratio (LR) and Wald tests suggest the overall significance 
of the results of the logistic regression analyses based on the six different dependent variables. None of the 11 industry dummies is statistically significant at the $10 \%$ level in the estimates using either the 2005 or the 2006 data. The industry effects are also not jointly significant. Therefore, industry appears to have no significant effect on SME decisions to apply for finance. Based on a similar dataset from a 1998 Australian survey, Cassar and Holmes (2003) also found that industry controls have a limited effect. Consequently, we remove the industry dummies from the the models.

\section{$<$ TABLE II HERE >}

As shown in Table II, the business focus dummies indicate the significance of the positive effects on finance-seeking decisions, though the effects are not consistent across the two sampling periods. For the 2005 sample, SMEs with a focus on operational measures, such as productivity or asset utilization, are more likely to apply for additional finance. The marginal effects of the focus variable on applying for equity and debt finance are $0.9 \%$ and $0.8 \%$, respectively. That is, Australian SMEs that focus on operational measures are $0.9 \%(0.8 \%)$ more likely to apply for additional equity (debt) than SMEs without an operational focus. In contrast, in 2006, a focus on financial measures, including profits and ROA, and a focus on cost measures, including cost per unit of output and inventory cost, are significantly associated with finance-seeking decisions. The marginal effects of these focus variables on finance seeking are relatively large, ranging from 5.4-5.6\% for a financial focus and $3.0-3.6 \%$ for a cost focus.

Therefore, an SME focus on growth has a positive effect on the finance-seeking decision. However, because the questions in the survey concerning business focus are not mutually exclusive, we group the responses concerning business focus into two categories. First, the focuses on financial, cost, operational and innovation measures, which we consider profitability or growth benchmarks, and second, the focuses on quality measures and human resources, as non-profitable or non-growth benchmarks.

SMEs that focus on quality measures, such as customer satisfaction and defect rates, are less likely to apply for additional debt in 2005 or finance in 2006 with a likelihood of $3.1 \%$ and $5.2-5.7 \%$, respectively. This effect is statistically significant across the two sampling periods. Across the two sampling periods, $49 \%$ and $51 \%$ of Australian SMEs in 2005 and in 2006 considered at least one of the four measures as 
a major business measure, with around 33\% and 34\% of SMEs in 2005 and 2006 considering quality as a major business measure. This may imply that the pursuit of profitability or growth is not as prevalent among small businesses as large businesses.

Another interesting finding is that the focus measures appear to have no significant effect on SME equity-seeking (as against debt-seeking) decisions. Given only 16\% of equity seeking in the survey targets sources other than existing owners and their friends, we can rightly consider most equity SMEs use in this analysis as internal finance. Pecking-order theory suggests that internally generated funds are the preferred sources of financing, followed by external debt and then external equity. Due to the costs of information and credit rationing, small businesses rely first on internal funding sources including owners and their family and friends (Bhaird and Lucey, 2010). SMEs generally exhaust these internal financing sources first to meet the needs of business operations, for example, working capital. Therefore, business focus measures may affect SME finance seeking more than normal finance seeking.

In contrast, three factors, planning, growth opportunity and foreign ownership, appear to have consistently significant effects across the six models. Business planning is a positive factor in seeking finance at the $1 \%$ level such that planning increases the probability of applying for debt by more than $10 \%$ and equity by $6.6 \%$. We can interpret this in at least three ways. First, business planning, comprising the planning process and the written business plan, is a proxy for a well-run business. Business planning not only legitimates the organization and enables better communication between entrepreneurs, internal and external stakeholders (Gibson and Cassar, 2005), but also helps in understanding the mechanics of the intended business and enables learning. A well-run business is then supposed to have a better understanding of when and where and how to apply for finance.

Furthermore, some studies confirm that planning is positively associated with performance. Therefore, the well-run business may have need for and confidence in applying for finance. Second, a start-up or early-stage SME may require a formal business plan that is used as a sales document to obtain angel finance. Third, planning can act as soft information for the SMEs, which can help alleviate the opacity of SMEs, thus giving easier access to finance resources. 
Growth opportunities also have significant positive effects on debt and equity seeking and finance seeking as a whole. Put differently, SMEs with growth opportunities appear to have much stronger demand for finance, increasing at the margin the probability of applying for debt by $10 \%$ and $3.5 \%$ for equity. This gives some evidence of the discrepancies in financing decisions between large and small firms. This could be because SMEs with growth opportunities are more likely to exhaust internal funds and require additional (external) funds (Riding et al., 2012). In addition, as most SMEs are unlisted, there is less concern about conflicts arising between shareholders and creditors. Foreign ownership has significant positive effects on debt/finance seeking, but negative effects on equity seeking. Roughly speaking, SMEs with some degree of foreign ownership are less likely to seek debt by $10 \%$, but more likely to seek equity by $6.7 \%$. These results accord with pecking-order theory, which suggests that SMEs with foreign ownership have more reliable internal funding. The results also indicate that family ownership raises the probability of acquiring debt by $8.1 \%$, but has no significant effect on seeking equity.

The significant effects of family ownership on debt seeking and the insignificant effects of family ownership on equity seeking can arise from the premise that ownermanager and family-controlled SMEs have a greater desire for control and exhibit an aversion to external equity. However, a more convincing interpretation is directly attributable to agency costs: the idea that the interests of the firm's managers and its shareholders, or the firm's shareholders and its creditors, do not perfectly align. We can actually interpret these two separate conflicts as an insider-outsider problem, that is, informational asymmetry aggravated by information opacity in the SME (Bhaird and Lucey, 2010). Therefore, owner-manager involvement in a family business should consolidate the firm and thus reduce agency costs, and give it more opportunities to gain access to resources from lenders (Lopez-Gracia and Sanchez-Andujar, 2007). The results show a positive association between size and debt seeking, but a negative association with equity seeking. $\mathrm{n}$ the sense of a size effect, trade-off theory rather than pecking-order theory can then better explain the financing-seeking behaviour of the SMEs. Firm age can also explain equity-seeking behaviour. However, the positive effects of firm age on debt seeking are not statistically significant in 2005 and 2006. Government assistance also exhibits a consistent and positive effect on SME financing decisions. However, we do not confirm the hypotheses on profitability; the 
signs of the estimated coefficients are all negative, but only that for equity seeking is statistically significant.

\section{Demand-side determinants of finance unavailability}

As shown in Table III, business focuses appears to have no consistent effect on finance unavailability for SMEs. We can see that at the margin, businesses that focus on financial and human resources are less likely rejected $(8.7 \%$ and $7.6 \%$, respectively). In contrast, SMEs that focus on innovation are more likely to obtain debt at a marginal value of $6.1 \%$. However, not all those effects are consistent across the models. This may imply that business objectives are not a major concern for finance providers in assessing the finance worthiness of SMEs.

\section{$<$ TABLE III HERE $>$}

We partly confirm that planning assists in obtaining finance. The positive effects of planning are mainly on equity availability with a marginal value of $12.2 \%$ and a pvalue of less than $1 \%$. This is consistent with the assumption that a SME may need a formal business plan that is then used as a sales document to obtain equity, especially for a start-up or early-stage SME. Surprisingly, profitability does not have a consistent effect on finance availability, which has a significant effect only in 2006. This is mainly because of the differences in the measurement of profitability. In the 2006 sample, profitability was whether a SME had an increase in profit from the previous year. However, in 2005, profitability was whether the SME was more profitable compared to its major competitors. Thus, the measurement of profitability in 2006 appears sounder.

The negative relation between size and finance application rejection implies that smaller finance-seeking firms are more likely rejected; the positive sign of the dummy variable, AGE01, suggests that a young small business is especially likely to be rejected. However, the effects of size and age are not significant on equity availability. Government assistance can also significantly assist a small business get its finance applications approved. The sign of the coefficient for growth opportunities in the finance unavailability models is positive. However, not all the effects are statistically significant. The growth opportunities imply a higher level of risk, thus reducing the possibilities of attaining finance for a SME. As discussed, growth opportunities 
appear to make a difference in finance seeking for both small and large firms. The SMEs with growth opportunities are more likely to apply for additional funding.

However, the phenomenon of the discouraged borrower may be at play. That is, some SMEs with growth opportunities that have not received acceptance of their finance applications in the past may be reluctant to apply for finance, even though they are in need of financing. In a similar vein, family ownership does not have a significant effect on finance unavailability either. We assume a family firm is capable of reducing agency costs, and providing collateral easily, as compared to a non-family firm. Therefore, the family firm should get easier access to finance. We can then attribute the insignificance of the effects of family ownership to its interaction with the phenomenon of the discouraged borrower. Unfortunately, there is no information about family ownership in the 2006 dataset.

\section{Concluding remarks}

This paper provided empirical evidence relating to the finance-seeking behaviour of Australian SMEs using a large ABS dataset. Our key motivation of the paper is that the factors determining the willingness of small businesses to seek finance lack evidence, especially in Australia. Based on capital structure theory, we investigate both these financing decisions and the demand-side-determinants of finance availability while making allowance for firm-specific factors, such as business objectives. In the first step, we examined the determinants of finance seeking. In the second step, we investigated the factors affecting finance unavailability.

Our findings show that business objectives significantly affect SME financeseeking decisions. SMEs that focus on profitability or growth have a strong willingness to seek additional finance. In comparison, SMEs that focus on the quality of their products or services are less likely to apply for additional finance. Furthermore, given the differences in financing behaviours between SMEs and large firms, we found pecking-order theory, not trade-off theory, is more useful to explain SME financial behaviour, which may provide evidence that SMEs still face financial constraints when pursuing growth especially for smaller SMEs. At the same time, there is also some evidence supporting agency cost theory on the grounds of the positive effects of family ownership on debt seeking. 
In our other main findings, apart from the well-discussed factors in the literature, such as firm size and age, some other factors also have significant effects on SME financing decisions. For example, a record of government assistance has a consistent effect on both finance seeking and finance availability, as a foreign investment. Of course, our analysis has some limitations. The first relates to data availability. For example, data on some responses gathered in 2005 is missing from 2006, such as information relating to family ownership. There is also regrettably no information about trade credit in the dataset, which could also affect SME financing behaviour. A second problem is that the measurement of some variables is rather dubious in the ABS methodology, especially profitability, as it is restricted to subjective qualitative assessments of profitability by respondents, not measures of actual profits.

\section{References}

Allen, D. (1993), “The pecking order hypothesis: Australian evidence”, Applied Financial Economics, Vol. 3 No. 2, pp. 101-112.

Bartholdy, J. and Mateus, C. (2011), “Debt and taxes”, International Review of Financial Analysis, Vol. 20 No. 3, pp. 177-189.

Beck, T., Demirguc-Kunt, A. and Maksimovic, V. (2005), "Financial and legal constraints to firm growth: Does size matter?”, Journal of Finance, Vol. 60 No. 1, pp. 137-177.

Beck, T., Demirguc-Kunt, A. \& Maksimovic, V. (2006), “The determinants of financing obstacles”, Journal of International Money and Finance, Vol. 25 No. 6, pp. 932-952.

Beck, T., Demirguc-Kunt, A. and Maksimovic, V. (2008), "Financing patterns around the world: Are small firms different?”, Journal of Financial Economics, Vol. 89 No. 3, pp. 467-487.

Bellucci, A., Borisov, A, and Zazzaro, A. (2010), "Does gender matter in bank-firm relationships? Evidence from small business lending”, Journal of Banking and Finance, Vol. 34 No. 12, pp. 2968-2984.

Berger, A.N. and Schaeck, K. (2011), "Small and medium-sized enterprises, bank relationship strength, and the use of venture capital”, Journal of Money, Credit and Banking, Vol. 43 No. 2-3, pp. 461490.

Berger, A.N. and Udell, G.F. (1998), “The economics of small business finance: The roles of private equity and debt markets in the financial growth cycle”, Journal of Banking and Finance, Vol. 22 No. 6-8, pp. 613-673.

Berger, A.N. and Udell, G.F. (2006), “A more complete conceptual framework for SME finance”, Journal of Banking and Finance, Vol. 30 No. 11, pp. 2945-2966.

Bhaird, C.M.A. (2010), “The Modigliani-Miller proposition after fifty years and its relation to entrepreneurial finance”, Strategic Change, Vol. 10 No. 1, pp. 9-28.

Bhaird, C.M.A. and Lucey, B. (2010), "Determinants of capital structure in Irish SMEs”, Small Business Economics, Vol. 35 No. 3, pp. 357-375.

Caneghem, T.V. and Campenhout, G.V. (2012), "Quantity and quality of information and SME financial structure”, Small Business Economics, Vol. 39 No. 2, pp. 341-358.

Cassar, G. and Holmes, S. (2003), "Capital structure and financing of SMEs: Australian evidence”, Accounting and Finance, Vol. 43 No. 2, pp. 123-147. 
Degryse, H., Goeij, P.D. and Kappert, P. (2012), "The impact of firm and industry characteristics on small firms’ capital structure, Small Business Economics, Vol. 38 No. 4, pp. 431-447.

Department of Innovation, Industry, Science and Research (2011), Key Statistics Australian Small Business, Commonwealth of Australia, Canberra.

Dietrich, A. (2012), "Explaining loan rate differentials between small and large companies: evidence from Switzerland”, Small Business Economics, Vol. 38 no. 4, pp. 481-494.

Fleming, G., Heaney, R. and McCosker, R. (2005), “Agency costs and ownership structure in Australia”, Pacific-Basin Finance Journal, Vol. 13 No. 1, pp. 29-52.

Fraser, S. (2009), "Is there ethnic discrimination in the UK market for small business credit?", International Small Business Journal, Vol. 27 No. 5, pp. 583-607.

Gibson, B. and Cassar, G. (2005), "Longitudinal analysis of relationships between planning and performance in small firms”, Small Business Economics, Vol. 25 No. 3, pp. 207-222.

Hamelin, A. (2011), "Small business groups enhance performance and promote stability, not expropriation. Evidence from French SMEs”, Journal of Banking and Finance, Vol. 35 No. 3, pp. 613-626.

Heyman, D., Deloof, M. and Ooghe, H. (2008), “The financial structure of privately held Belgian firms, Small Business Economics, Vol. 30 No. 3, pp. 301-313.

Iturralde, T., Maseda, A. and San-Jose, L. (2010), "Empirical evidence of banking relationships for Spanish SMEs”, International Small Business Journal, Vol. 28 No. 3, 274-295.

Lopez-Gracia, J. and Sanchez-Andujar, S. (2007), "Financial structure of the family business: evidence from a group of small Spanish firms”, Family Business Review, Vol. 20 No. 4, pp. 269-287.

Lopez-Gracia, J. and Sogorb-Mira, F. (2008), “Testing trade-off and pecking order theories financing SMEs”, Small Business Economics, Vol. 31 No. 2, pp. 117-136.

Niskanen, M. and Niskanen, J. (2010), "Small business borrowing and the owner-manager agency costs: evidence on Finnish data”, Journal of Small Business Management, Vol. 48 No. 1, pp. 1631.

Psillaki, M. and Daskalakis, N. (2009), “Are the determinants of capital structure country or firm specific?”, Small Business Economics, Vol. 33 No. 3, pp. 319-333.

Riding, A., Orser, B. J., Spence, M. and Belanger, B. (2012), "Financing new venture exporters”, Small Business Economics, Vol. 38 No. 2, pp. 147-163.

Roberts, M.R. and Sufi, A. (2009), “Control rights and capital structure: an empirical investigation”, Journal of Finance, Vol. 64 No. 4, pp. 1657-1695.

Romano, C. A., Tanewski, G.A. and Smyrnios, K.X. (2001), “Capital structure decision making: A model for family business”, Journal of Business Venturing, Vol. 16 No. 3, pp. 285-310.

Roper, S. and Scott, J.M. (2009), “Perceived financial barriers and the start-up decision”, International Small Business Journal, Vol. 27 No. 2, pp. 149-171.

Serrasqueiro, Z.S. and Nunes, P.M. (2008), "Performance and size: Empirical evidence from Portuguese SMEs”, Small Business Economics, Vol. 31 No. 2: pp. 195-217.

Tong, G. and Green, C.J. (2005), "Pecking order or trade-off hypothesis? Evidence on the capital structure of Chinese companies, Applied Economics, Vol. 37 No. 19, pp. 2179-2189.

Vos, E., Yeh, A.J.Y., Carter, S. and Tagg, S. (2007), “The happy story of small business financing”, Journal of Banking and Finance, Vol. 31 No. 9, pp. 2648-2672. 